\title{
Imitative participation and the politics of 'joining in': paid work as a methodological issue. ${ }^{1}$
}

\author{
Hannah Knox (University of Manchester)
}

In this paper I explore the ways in which participation as a research methodology is challenged by new kinds of anthropological enquiry and consider, from my own experiences, what the implications of these challenges might be for our expectations of how participation contributes to the construction of anthropological knowledge. I look at the ways in which different forms of participation affect what it is possible for the ethnographer to know, and look at the value attributed to not only what we know but also how we come to know it. This has important implications for our understanding of the interrelationship between different categories of knowledge and how to situate anthropological knowledge in relation to the processes of participation from which it is in large part derived.

Although this paper is a contribution to a special issue about 'new' methods in the anthropology of science and technology, I have chosen to discuss a core method of the discipline: participant observation. I explore the ways in which participation as a research methodology is challenged by new kinds of anthropological enquiry and consider, from my own experiences, what the implications of these challenges might be for our expectations of how participation contributes to the construction of anthropological knowledge. The desire to write this paper arose out of my own experiences of fieldwork at home and in particular a number of incidents which highlighted the fragility of the division between participant observer and native actor, between observer and observed and, more specifically, between two different kinds of participation: productive and imitative. I argue that by exploring these distinctions in the context of auto-anthropology we can further attune ourselves to the relationship between our practices as participants and our practices as theorists of culture and society.

There is a burgeoning interest amongst anthropologists towards the study of science and technology (Downey, Dumit, and Williams 1995; Franklin 1995; Schiffer 2001; Terrell 2000). One of the implications of this shift in focus is that anthropologists increasingly find themselves sharing their own theories about the world with the people with whom they choose to do research with (Marcus 2000; Nader 1996; Rabinow 1996). Strathern's notion of auto-anthropology clearly articulates the difference between an idea of anthropology at home which concerns itself with the shared cultural background of observer and observed, and the issues facing those of us doing an anthropology of science and technology. In The Limits of Auto-Anthropology Strathern (1987) explores the peculiarities of this particular kind of anthropology at

\footnotetext{
${ }^{1}$ I would like to thank the two anonymous referees for their helpful and insightful comments.
} 
home by comparing her experiences of producing and writing ethnographic texts about the UK and Melanesia. In doing so Strathern draws out some of the ways in which auto-anthropology forces us to reflect upon and challenge our expectations about authorship in ethnographic writing.

Strathern's paper focuses on contemporary debates of the late 80's, which demanded that anthropologists acknowledge their representational practices and called for them to explore the implications of different kinds of writing for the production of knowledge. She argued that the author/writer function, which is a central feature of an anthropological form of knowledge production, is necessarily reorganized when doing auto-anthropology. The function of ethnography has traditionally been, firstly, to describe and translate 'the other' to an audience 'at home', and then to theorize and analyse these descriptions after the event and at a distance. What auto-anthropology makes very apparent, however, is that the description is always already necessarily an analysis. An interpretation of the anthropologist's own society must always lie alongside the interpretations that the subjects of research have provided themselves. Auto-anthropology points not only to similarities between researchers and their subjects but draws attention to the extent to which the subjects of analysis share theories about the organization of knowledge about the world with the discipline of anthropology. The notion of auto-anthropology and its limits is, like other literature on anthropology at home (Amit and European Association of Social Anthropologists 2000; Jackson 1987), concerned primarily with the question of shared understanding and differentiated knowledge. In this paper I step back to consider the centrality of participation as method and the issues that contemporary fieldwork in science and technology raises for our status as participant observers. Understanding the issues surrounding participation inevitably returns us to the kinds of knowledge that participatory research produces.

The participatory aspects of anthropological research are reorganized in many contemporary research settings where participatory fieldwork and the work of the people who one is researching become blurred. The argument made in this paper concerns a setting which could be considered auto-anthropological, and where the research subjects shared many of the same preconceptions about the organization of knowledge about the world as the anthropologist. But the points made regarding participation in research settings may well be applicable to wider circumstances where the researcher finds him or herself blurring the distinction between work as a fieldworker and work as a productive participant.

The example that this paper draws upon is a situation where, as an anthropologist, I had to deviate from what I saw as an anthropological idea of imitative participation and productively engage in the activities of my research subjects. This was also a situation where I found myself in a process of mutual creation of practice as part of my role as ethnographer. The situation I describe came about during fieldwork I carried out at a web design company that specializes in online advertising campaigns. For the purposes of this paper I will call the company 'Planet'. ${ }^{2}$ It was ten months into my fieldwork when I gained access to this firm, and I was keen to get some hands on experience of working life in the 'digital industries'. I had been conducting fieldwork on the emergence and development of the new media industry in Manchester, and up

\footnotetext{
${ }^{2}$ Both the names of the organization and its employees have been changed.
} 
until this point had focused my attentions on the activities of a public sector organization that provided business support for people working in this field.

Planet was made up of ten full time members of staff, five of whom had jointly set up the company and held directorial positions. It had been through a conversation with one of the directors, 'Andy', that I had been invited to do research in the organization. I had previously interviewed another director and had met other employees of the firm on various occasions over the previous few months. Consequently, when I arrived on the Monday morning, in the midst of hectic preparations for their first birthday party, I was warmly invited in, shown around and told to make myself at home. It soon became very clear, however, that despite my explanations of what I wished to achieve from fieldwork, I was not being treated in the manner which I had expected. It transpired early on that I was being pigeonholed as a graduate placement, a category that the firm's staff were used to. It was only towards the end of my time with Planet that I discovered that Andy had not transmitted my meticulously described purposes for access to the other staff members before my arrival. In addition to this miscommunication, the spatial layout of the firm was such that people were organized into small rooms according to their role in the company. The 'creatives' were all based together in one room, the account managers in another, and the new business manager and office administrator in another. This particular division of space, coupled with the use of email for much communication even within the offices meant that keeping on top of company activities was sometimes intrusive, usually interruptive and often impossible. It was awkward to gain access to the meetings and discussions that interested me about the organization. The opportunities I had to talk to people were either formal allocations of time (such as, 'you can spend an hour or so sitting with so and so'); or limited snippets of conversation, for example, between telephone calls, whilst people used the photocopier, or as they stood waiting by the printer. Participation was organized 'on a need to know basis'.

In order to gain access I had suggested that I might assist with bits of work that needed doing. As a $\mathrm{PhD}$ student I was unable to offer any financial recompense in return for the privilege of being allowed access to the firm. Offering my services had the dual effect of giving something in return for my time in the firm, and giving me greater access to the meetings which occurred around the different web development projects. Despite initially being categorized as a student placement, my role as a researcher was gradually realized and increasingly drawn upon by staff, to inform their activities such as the writing of pitch proposals, informing client meetings and understanding competitor activities. I had worked hard to make myself useful, in order to facilitate my participation in the workplace. The most successful way of becoming involved was if people perceived that my involvement was useful for their needs.

Whilst most of the staff were not very familiar with anthropology, they were strong advocates of social research and its potential to inform their understanding of their clients' audiences, particularly in the context of marketing. My activities started out as odd jobs around the office, but after a while I began to do some research on the internet for them, trawling for snippets of information which they needed for the

\footnotetext{
${ }^{3}$ This was a phrase that was used by employees and managers to indicate the basis of involvement in formal and informal meetings. The 'need' was determined primarily by whether or not the person in question was working on the project that the meeting was about.
} 
development of briefs. Whilst the work that I did during this time gave me a greater and deeper understanding of the activities of the company, it also confused an opposition that I had set up between observer as outsider or peripheral participant and a worker who was clearly (in my mind) an insider. During a chat with one of the directors she explained to me her discomfort at my doing unpaid work for them. If I was to continue doing it, then they wished to pay me for it. I was in a situation where I could either be positioned very peripherally and not engage in the activities of the firm or I could participate and be included. I opted for the latter.

I was worried that the wage-labour relationship would create barriers in my ability to do field research with the company and would compromise my position as observer in the organization. I had various concerns: that I would not have sufficient time to pursue areas that I was interested in exploring which lay outside the flow of work (such as more informal conversations with people); that I would become drawn into the agendas of the company employees as Mosse (2001: 178) experienced; and that the kind of work that I was expected to produce for the company undermined the kind of research that I was interested in doing. I soon realized, however, that the relationship that I had agreed to partake in was revealing things that I would not otherwise have been so attuned to. The form of my involvement was sanctioned by, and thus revealed, particular kinds of expectations regarding fair work practices and a blurring between autonomy and control in this work environment. It became clear to me that the company did not have the rigid borders of insider and outsider that I had assumed. The vocational histories of employees were not organized around a standardized path of professionalization, and the primary organizational philosophy was one that embraced the incorporation of new ideas and diverse expertise. My position as an employee enabled me to see more clearly how contractors, freelancers and clients were all invited into the organization, were drinking partners and friends of employees as well as being their colleagues. The organizational form of the firm was revealed to be self-consciously undefined, the result of a decision by the directors to let the structure of the firm evolve naturally over time. My incorporation as a paid employee revealed the ways in which wider expectations about fairness and reciprocity informed the way in which the company was organized as well as the limits of these ideals in a market setting. In this light, and in the context of attempts to be open, fair and non-exploitative in their working practices, my recompense in their eyes was not problematic. The problem surrounding payment, it seemed, lay with my own conceptualizations of participation and my need to maintain a necessary level of 'distance' between what I was doing and what the company employees were doing.

I would suggest that the main reason for my unease was that my position as a paid employee of the organization had the effect of disrupting my own expectations of what it meant to be a peripheral participant (Wenger 1998: 100) in the firm's activities. Working 'down' frequently gives anthropologists the freedom to focus on their own work, remunerating the people they do the research with, with gifts, payment, or offers of advocacy and help. But sometimes anthropologists must not only create a charade of work to gain access to an organization but must engage in work itself, the 'real' thing (Graham 1995). Anthropologists have recognized the importance of experience in understanding, and have engaged with the ways in which, as researchers, we can gain embodied knowledge through mimetic participation (Dilley 1999). But calls for anthropologists to acknowledge the ways in which we come to know through embodied experience have not provided any kind of cultural critique of the idea of researcher as mimetic or imitative actor, though plenty has been 
written about mimesis as a means through which subjects of research learn from one another (Fortes 1938; Mead (1930) 1975), and the wider cultural politics that mimesis entails (Taussig 1993). By accepting payment, I was able to participate more fully in the environment I was researching, and I also felt that my participation was not always simply imitative. Being paid meant that I was potentially blurring important distinctions which I had set up between the focus, meaning and perspective of my gaze and the focus, meaning and perspectives of those I was researching. I was being employed in part on the basis of my expertise as a researcher. Although other company employees and I shared a commitment to many things, including creative and critical thinking and ethical work practices, it was clear that we had previously been engaged in different projects with different outcomes. Remuneration for work meant that I felt my commitments risked being incorporated into the company, and I needed to be wary of what this might entail.

By initially denying the possibility that my imitative activities might actually be somehow productive from the point of view of the people who I was researching, I had set up the conditions through which a monetary remuneration for my 'work' seemed problematic. My initial assumptions about imitative participation had overly emphasized the learning dimension of mimetic relationships and ignored the effects and outcomes of imitative participation, the objects that are produced as a result of imitations of work and the ability of the researcher to make active contributions to the people he or she is working with. ${ }^{4}$ Being paid was an explicit means of incorporation into the company. No longer was my role as a participant observer simply imitative and focused on the production of knowledge, it was becoming reconfigured to be about the production of websites.

Receiving payment also reorganized my commitments and responsibilities in conducting research. Specifically, the introduction of payment forced a reorganization of the relationship I had with the company workers. I had initially envisaged the power relationship between myself and the people I would be doing research with as potentially problematic in the terms that other anthropologists might normally see it. I imagined that I would inevitably be in a position of power because of the information I would be party to, and I was aware of the responsibility for representation that I would have. Rather than my providing monetary payment to the company for a potentially parasitic practice of research, I had hoped that my 'payment' might be in kind through useful engagement in the work of the firm. In this way I would be able to make some kind of exchange for the information and knowledge that they were giving me. However, when they then wished to pay me, not only was I no longer giving anything in exchange for the experience that I would be taking away, I was receiving money from them as well. This might be seen as a broader issue in the study of elites where classic power relations between researcher and researched are reversed. Nevertheless, even in contexts where anthropologists work with people who are not as powerful as we are, we still have a responsibility towards our research subjects. For example, I was concerned that people would forget or not realize that I was still hoping to draw on my experiences of this productive participation for my research, which raised ethical considerations about how to make the research exercise visible to research participants.

\footnotetext{
4 The researcher is not simply a passive observer but becomes situated in his or her research environment in ways which require personal evaluations about the kinds of participation that are acceptable or ethical and reflections on the basis upon which these evaluations are made.
} 
Because anthropological participation necessarily has a purpose-namely, to understand, describe and interpret - which is different to the purpose of the actions of the people with whom we do research, our participation for the purposes of research is always constructed as imitative. The fact that we are not engaged in activities for the same reason as research participants is the basis of our analysis. As Mosse (2001) argues, by shifting from what I have called imitative participation, that is participation for the purposes of research, to full productive participation (in his case as a development specialist), ${ }^{5}$ anthropologists are supposed to gain insight into the settings of our research. It is from this 'distance' that we are apparently able to gain an analytical appreciation, marrying our experiences of mimetic practice with what people say they do, and what anthropologists have seen other people do in similar situations in other parts of the world.

When we stop participating in a mimetic sense and start participating according to the norms, rules, and purposes of the people with whom we are working, the gap between outsider and insider seems to become problematic. When the gap threatens to close, we are required to reappraise our role as anthropologists and the nature of what we are producing. When participation is no longer clearly an imitation of another and rather, becomes governed by norms, values, decision-making processes and sentiments which also inform participants' actions, the anthropologist can find him or herself experiencing an identity crisis. Just as in the case of auto-anthropology, the limits of description are challenged when the anthropological project seems to overlap with the project of research participants. This identity crisis can, however, become a source of great reflective insight. Whilst self-reflexivity can be seen as an elitist and exclusionary exercise in academic introspection, and a source of anthropological crisis, it holds the potential to be much more than this. In the context of autoanthropology, this self-reflection provides a source not only of insight into our own practices as anthropologists, but also those of our research participants who share substantially similar theoretical suppositions about how we should come to know the world and inhabit the world through certain kinds of participation which create on the one hand distance, and on the other, incorporation.

In the context of the web design company I was incorporated into the company through payment. This incorporation seemed to risk closing the distance through which analytical insight might be gained. But this leads to the question "what is the nature of this "distance" or "gap" that analysis requires?' In ethnographic research, the critique of objectivity as a reasonable aim has led people to explore other ways through which they can claim that their knowledge has value (Clifford and Marcus 1986). But there is still a widespread commitment to the production of knowledge through systematic analysis of material that lies outside the theory used to analyse it. Interrogation of my experiences led me to realize, however, that this gap is not determined by cultural similarity or difference between ourselves and the people we research. The 'gap' between theory and object of research does not exist prior to the intersection of theory and practice, but is produced in the act of analysis as these

\footnotetext{
${ }^{5}$ By this I mean that usually imitation is not normally problematic because it is done in the knowledge that the anthropologist is not trying to 'become' the researched. Imitation in itself implies a non-reality, a sense that the anthropologist can retain 'distance' by doing activities in an imitative rather than productive sense. By engaging in productive participation, we run the risk that we either forget, or do not have time, to reflect adequately on our observations thus shrinking the distance between researcher and researched.
} 
activities are separated out in order that a relationship can be posited between the two. My qualms about the research relationship were rooted in a notion of distance that was absolute. Erasing the distance created through difference seemed to hold the risk of erasing the possibility for critical analysis. The fact that I was doing research in a setting where I shared a cultural, educational and generational similarity with the people about whom I was doing research made it seem as if this gap might close. This threat, however, challenged me to consider the nature of the 'gap' itself and to realize that it is a commitment to analysis that creates the sense of distance and not the degree of shared knowledge between a researcher and the subjects of her research.

The example I have given shows the way in which the potential of 'imitative' or 'productive' forms of participation to generate knowledge is not determined by the relative proximity we have to our research participants as a geographical or cultural measure. Rather our knowledge derives from the ways that we, as researchers, conduct our relationships with those researched, in relation to expectations about the politics and purpose of our own projects. Imitative participation implies a one-way relationship between researcher and researched whereby researchers gain knowledge by copying the activities of the people they research and thus assimilate that knowledge into the project of anthropology. We should not, however, see imitative participation simply as an activity that we do, and productive participation as a more 'real' activity of research participants. It is more useful to recognize that our identities as anthropologists are constituted, as are the identities of research participants, by specific negotiations of mimesis and productive action in how we come to know and how we come to be. It is our job as anthropologists to be aware of the form that these negotiations take. It is in this way that the participatory nature of fieldwork relates back to Strathern's notion of auto-anthropology. Our participatory practices are tied up with truth claims and claims about validity and understanding which derive from an idea of perspective which, in turn, produces a particular sense of distance between ourselves and our research informants. By recognizing and interrogating the practices through which claims over the 'truth', 'validity', or salience of anthropological knowledge are sustained through our methodological practices, we might be better equipped to negotiate our roles as anthropologists in the field, in circumstances that might at first seem awkward, uncomfortable or compromising. Furthermore, this attentiveness to method might allow us to answer the critics of postmodernist anthropology (D'Andrade 1995; Spiro 1996), through a reflexive engagement with the politics of truth claims which neither compromises the importance of recognizing positionality nor denies the centrality of empirical research for anthropology. That is, rather than responding to a critique of empiricism by abandoning the project of interpretation, this paper argues that we would do better to continue the task of turning our interpretations inwards on ourselves as well as outwards, particularly in settings where our own assumptions about the value of our research findings appear to be challenged. In contexts of auto-anthropology, the inside (the discipline of anthropology) and the outside (the context of research) are not always clearly differentiated, and so self-reflexivity will also inform our understandings of the settings in which we find ourselves as fieldworkers.

A critical awareness of our participatory practices thus allows us to interrogate, in certain settings, not only our own theories but also our research participants' theories of themselves. This paper has shown how the anthropological participatory method encourages us to interpret our practices as existing outside or at a distance from the activities of our research participants. But if we are to continue to conduct research in 
the organizations and institutions of science and technology, then we must also be aware of the shifts in power relations that we must negotiate and the implications this has for our situation as outsiders or insiders. If we are going to continue our research into the institutions of science and technology, it is likely that we will have to engage in some kind of productive participation in our field sites whether paid or not. The emerging circumstances in which we find ourselves participating will require us to continue to challenge the political, ethical and theoretical bases upon which we attribute value to different kinds of involvement and engagement and the implications for the production of scientific and social scientific knowledge.

\section{References}

Amit, V. \& European Association of Social Anthropologists. 2000. Constructing the field : ethnographic fieldwork in the contemporary world. London, New York: Routledge.

Clifford, J. \& G.E. Marcus. 1986. Writing culture: the poetics and politics of ethnography. Berkeley, Calif., London: University of California Press.

D'Andrade, R.G. 1995. Moral models in anthropology. Current Anthropology 36, 399-408.

Dilley, R. 1999. Ways of knowing, forms of power. Cultural Dynamics 11, 33-56.

Downey, G.L., J. Dumit \& S. Williams. 1995. Cyborg anthropology. Cultural Anthropology 10, 264-69.

Fortes, M. 1938. Social and psychological aspects of education in Taleland. London: Oxford University Press.

Franklin, S. 1995. Science as culture, cultures of science. Annual Review of Anthropology 24, 163-84.

Graham, L. 1995. On the line at Subaru-Isuzu: the Japanese model and the American worker. Ithaca, NY, London: ILR Press.

Jackson, A. 1987. Anthropology at home. London: Tavistock.

Marcus, G.E. 2000. Para-sites: a casebook against cynical reason. Chicago, Ill., London: University of Chicago Press.

Mead, M. (1930) 1975. Growing up in New Guinea: a comparative study of primitive education. New York: Morrow.

Mosse, D. 2001. Social research in rural development projects. In Inside organizations: anthropologists at work (eds) D.N. Gellner \& E. Hirsch, 159-81. Oxford, New York: Berg.

Nader, L. 1996. Naked science: anthropological inquiry into boundaries, power, and knowledge. New York, London: Routledge.

Rabinow, P. 1996. Representations are social facts: modernity and post-modernity in anthropology. In Essays on the anthropology of reason, 28-57. Princeton, N.J., Chichester: Princeton University Press.

Schiffer, M.B. 2001. Anthropological perspectives on technology. Albuquerque: University of New Mexico Press. 
Spiro, M. 1996. Postmodernist anthropology, subjectivity, and science: a modernist critique. Comparative Studies in Society and History 38, 759-80.

Strathern, M. 1987. The limits of auto-anthropology. In Anthropology at home (ed) A. Jackson, 16-37. London: Tavistock.

Taussig, M.T. 1993. Mimesis and alterity: a particular history of the senses. New York, London: Routlege.

Terrell, J.E. 2000. Anthropological knowledge and scientific fact. American Anthropologist 102, 808-17.

Wenger, E. 1998. Communities of practice. Cambridge: Cambridge University Press.

\section{About the author}

Hannah Knox completed her $\mathrm{PhD}$ in social anthropology at the University of Manchester in 2003. Her doctoral research explored the cultural dynamics of projects of technological, social and economic change through an ethnographic study of the development of new media industries in Manchester. Hannah has recently started work as a Research Associate at the ESRC Centre for Research on Socio Cultural Change (CRESC) at the University of Manchester. 